\title{
The effects of feeding 3-nitrooxypropanol on methane emissions and productivity of Holstein cows in mid lactation
}

\author{
J. Haisan, ${ }^{\star}$ Y. Sun, ${ }^{\star}$ L. L. Guan, ${ }^{\star}$ K. A. Beauchemin,† A. Iwaasa,‡ S. Duval,§ D. R. Barreda, ${ }^{\star}$ and M. Oba ${ }^{\star 1}$ \\ *Department of Agricultural, Food and Nutritional Science, University of Alberta, Edmonton, Alberta T6G 2P5, Canada \\ †Agriculture and Agri-Food Canada, Lethbridge, Alberta T1J 4B1, Canada \\ $\ddagger$ Agriculture and Agri-Food Canada, Swift Current, Saskatchewan S9H 3X2, Canada \\ §DSM Nutritional Products Ltd., Centre de Recherche en Nutrition Animale, 1 Bd d'Alsace, Village-Neuf BP 170, France
}

\begin{abstract}
The objective of the current study was to determine the effects of adding 3-nitrooxypropanol to the diet of lactating Holstein cows on methane emissions, rumen fermentation, ruminal microbial profile, and milk production. Twelve ruminally cannulated Holstein cows in midlactation were used in a crossover design study with 28 -d periods. Cows were fed a diet containing $38 \%$ forage on a dry matter basis with either $2,500 \mathrm{mg} / \mathrm{d}$ of 3 -nitrooxypropanol (fed as $25 \mathrm{~g}$ of $10 \%$ 3-nitrooxypropanol on silicon dioxide) or $25 \mathrm{~g} / \mathrm{d}$ of silicon dioxide (control). After a 21-d diet adaptation period, dry matter intake (DMI) and milk yield were recorded daily. Rumen fluid and digesta were collected on d 22 and 28 for volatile fatty acid analysis and microbial profiling. Enteric methane emissions were measured on d 23 to 27 using the sulfur hexafluoride tracer gas technique. Feeding 3-nitrooxypropanol did not affect DMI; however, methane production was reduced from 17.8 to $7.18 \mathrm{~g} / \mathrm{kg}$ of DMI. No change in milk or milk component yields was observed, but cows fed 3-nitrooxypropanol gained more body weight than control cows (1.06 vs. $0.39 \mathrm{~kg} / \mathrm{d}$ ). Concentrations of total volatile fatty acids in ruminal fluid were not affected by treatment, but a reduction in acetate proportion and a tendency for an increase in propionate proportion was noted. As such, a reduction in the acetate-to-propionate ratio was observed (2.02 vs. 2.36). Protozoa counts were not affected by treatment; however, a reduction in methanogen copy count number was observed when 3-nitrooxypropanol was fed (0.95 vs. $2.69 \times 10^{8} / \mathrm{g}$ of rumen digesta). The data showed that feeding 3-nitrooxypropanol to lactating dairy cows at $2,500 \mathrm{mg} / \mathrm{d}$ can reduce methane emissions without compromising DMI or milk production.
\end{abstract}

Key words: 3-nitrooxypropanol, enteric methane emission, milk production, methanogen

Received December 14, 2013.

Accepted January 26, 2014.

${ }^{1}$ Corresponding author: moba@ualberta.ca

\section{INTRODUCTION}

Demand exists to reduce greenhouse gas emissions generated by the agricultural sector, in particular, the livestock industry. In recent years, it has been estimated that cattle alone are responsible for 11 to $17 \%$ of the methane generated globally (Beauchemin et al., 2009a). As methane has a global warming potential 21 times that of carbon dioxide (United Nations, 2013), the environmental importance of emissions is self-evident. Another consideration is that between 2 and $12 \%$ of the ingested gross energy of cattle can be lost to methane (Johnson and Johnson, 1995), a loss of energy that could potentially be used by the animal. Enteric methane emissions from cattle can be reduced through dietary techniques such as improving forage quality, higher inclusion of concentrates in the diet and feeding lipids (Martin et al., 2010; Eckard et al., 2012). Additionally, previous research has shown that natural compounds, such as tannins and saponins, and synthetic dietary compounds, such as ionophores, can reduce methane emissions from ruminants through inhibition of methanogenesis or by shifting fermentation pathways to promote alternative hydrogen sinks, such as propionate production, thus reducing methane emissions (McAllister and Newbold, 2008; Martin et al., 2010).

Recently, several molecules, substituted at various positions with at least one nitrooxy group, were identified as potential inhibitors of enteric methanogenesis (Duval and Kindermann, 2012). One such compound, 3-nitrooxypropanol (NOP), was developed from predecessor compounds (ethyl 3-nitrooxy propionate; WO2011/070133 and 3-azido-propionic acid ethyl ester), which were identified from an in vitro rumen simulation screening assay (Soliva et al., 2011). The NOP exhibited a significantly higher potential to reduce methanogenesis in vitro than the well-known model compound bromoethanesulfonate (Soliva et al., 2011). Bromoethanesulfonate is a coenzyme $M$ ana$\log$ (Gunsalus et al., 1978) with very specific activity against methanogens that inhibits the reduction of 
methyl-coenzyme $\mathrm{M}$ to methane during the last step of methanogenesis (Immig, 1996).

Research using a rumen simulation technique showed that NOP is capable of reducing methane production (Romero Perez et al., 2013b). Furthermore, when NOP was directly dosed into the rumen of sheep (MartinezFernandez et al., 2013) and lactating dairy cows (Reynolds et al., 2013) or fed once daily to beef cattle (Romero Perez et al., 2013a), methane emissions were reduced and an increase in propionate concentration was observed, suggesting a shift in rumen fermentation. However, the effect of NOP on methanogen numbers or microbial profile was not reported or consistently demonstrated in those previous studies.

Although use of NOP is a promising approach to reduce enteric methane emissions from ruminants, further studies are required to confirm its efficacy in reducing methane emissions while evaluating its effects on rumen fermentation and animal productivity. It was hypothesized that lactating dairy cows fed NOP would have reduced methane emissions; hence, more energy would be available for milk production. The objectives of the present study were to determine the effects of NOP on methane emissions, animal performance, rumen fermentation, and rumen microbial profile of lactating dairy cows.

\section{MATERIALS AND METHODS}

All procedures were preapproved by the Animal Care and Use Committee for Livestock at the University of Alberta and conducted according to the guidelines of the Canadian Council of Animal Care (Ottawa, ON, Canada). The use of the biochemical compound [10\% NOP on silicon dioxide $\left.\left(\mathrm{SiO}_{2}\right)\right]$, developed by DSM Nutritional Products Ltd. (Kaiseraugst, Switzerland) in the diet of lactating dairy cows at $25 \mathrm{~g} / \mathrm{d}$ was preapproved by the Veterinary Drugs Directorate Division (Health Canada, Ottawa, ON, Canada) for research. According to their instructions, milk was discarded for the duration of the study and an additional 14-d milk withdrawal period was implemented upon completion of the study.

\section{Experimental Design, Diet, and Treatment}

Twelve lactating Holstein cows with ruminal cannulas (Bar Diamond Inc., Parma, ID) were used in a crossover design study with 28-d periods consisting of $21 \mathrm{~d}$ of adaptation and $7 \mathrm{~d}$ of data and sample collection. Cows were separated into 2 groups based on the pre-experiment DIM (means \pm SD: Group $1=100 \pm$ 5.4, Group $2=76 \pm 10.1$ ). Group 1 had 4 multiparous and 4 primiparous cows and group 2 had 2 multiparous and 2 primiparous cows, and they were randomly assigned to the treatment sequence. Pre-experiment BW $($ means $\pm \mathrm{SD})$ were $591.5 \pm 58.9$ and $567.5 \pm 93.5 \mathrm{~kg}$ for groups 1 and 2, respectively. The study was conducted using 2 groups of cows to facilitate methane measurement; however, we did not have sufficient supplies to measure methane emission for all cows at once, thus the whole study protocol was staggered by $7 \mathrm{~d}$ between the 2 groups. Cows were housed individually in tiestalls and milked twice daily in their stalls at 0400 and $1600 \mathrm{~h}$.

All cows were fed the same diet as a TMR (Table 1), ad libitum, once daily at $0900 \mathrm{~h}$, allowing for $5 \%$ refusals throughout the study, and had free access to water. The diet was formulated to provide adequate $\mathrm{ME}$ and MP for a $650-\mathrm{kg}$ cow producing $40 \mathrm{~kg}$ of milk per day (NRC, 2001) and to ensure ME and MP intake did not limit milk production of all cows. Cows were fed either $\mathrm{SiO}_{2}$ as a control $(\mathbf{C O N})$ or NOP at $25 \mathrm{~g} / \mathrm{d}$, resulting in 0 and $2,500 \mathrm{mg} / \mathrm{d}$ of 3-nitrooxypropanol, respectively. Both NOP and $\mathrm{SiO}_{2}$, in powder form, were hand-mixed with $80 \mathrm{~g}$ of ground barley grain, 50 $\mathrm{g}$ of wet molasses, and $40 \mathrm{~g}$ of canola oil to improve adhesion to feed particles and palatability. Cows were assigned to either treatment on d 1 of each period without incremental adaptation. To avoid contamination of feeding equipment at the farm, each treatment mixture was applied by hand-mixing into the TMR once daily, within $30 \mathrm{~min}$ of feeding. This protocol also simulated an on-farm feeding scenario, allowing for consumption of NOP throughout the day as feed is consumed.

\section{Data and Sample Collection}

The amount of feed offered and refused was recorded for individual cows at the time of feeding, and the amount of TMR fed was adjusted daily to maintain $5 \%$ refusals. The NOP content in refusals was not determined. Dietary ingredients were sampled (approximately $500 \mathrm{~g}$ ) on d 25 to 27 and composited for each period to determine the chemical composition of the diet. All samples were dried for $72 \mathrm{~h}$ at $55^{\circ} \mathrm{C}$ in a forced-air oven and stored at $4^{\circ} \mathrm{C}$ until further analysis. Additionally, diets were adjusted weekly to maintain the same concentrate-to-forage ratio on a DM basis. Body weight was measured at the beginning and end of each period. Milk yield was recorded at every milking, and milk samples (approximately $50 \mathrm{~mL}$ ) were taken from 6 consecutive milkings from d 25 to 27 and stored at $4^{\circ} \mathrm{C}$ with 2-bromo-2-nitropropane-1,3-diol until milk composition analysis.

Rumen digesta were collected through a rumen cannula, from 5 locations in the rumen (cranial dorsal, cranial ventral, central rumen, caudal dorsal, and caudal 
Table 1. Ingredients and nutrition composition of experimental diet

\begin{tabular}{lc}
\hline $\begin{array}{l}\text { Item, } \% \text { DM } \\
\text { (unless otherwise noted) }\end{array}$ & Total \\
\hline Ingredient & \\
Barley silage & 37.9 \\
Dry ground corn & 31.4 \\
Canola meal & 11.3 \\
Corn gluten meal & 8.4 \\
Beet pulp & 6.2 \\
Canola oil & 1.4 \\
Limestone & 1.2 \\
Salt & 1.2 \\
Calcium diphosphate & 0.6 \\
Magnesium oxide & 0.3 \\
Mineral and vitamin premix ${ }^{1}$ & 0.1 \\
Nutrient composition & \\
DM, \% & 53.5 \\
OM & 90.8 \\
CP & 19.6 \\
NDF & 26.5 \\
ADF & 18.4 \\
Starch & 26.8 \\
Ether extracts & 5.0 \\
\hline
\end{tabular}

${ }^{1}$ Contained $17,413 \mathrm{KIU} / \mathrm{kg}$ of vitamin $\mathrm{A}, 1,714 \mathrm{KIU} / \mathrm{kg}$ of vitamin $\mathrm{D}_{3}$, $57 \mathrm{KIU} / \mathrm{kg}$ of vitamin E, $579 \mathrm{mg} / \mathrm{kg}$ of Co, $28,586 \mathrm{mg} / \mathrm{kg}$ of $\mathrm{Cu}, 1,286$ $\mathrm{mg} / \mathrm{kg}$ of I, $51,429 \mathrm{mg} / \mathrm{kg}$ of Mn, $85,714 \mathrm{mg} / \mathrm{kg}$ of Zn, and $571 \mathrm{mg} /$ $\mathrm{kg}$ of Se.

ventral) before feeding at $0830 \mathrm{~h}$ on $\mathrm{d} 22$ and 28 . Digesta samples were collected by grabbing a handful of rumen digesta and transferring to a 50-mL sterile tube for each location. The tubes were immediately frozen on dry ice and stored at $-80^{\circ} \mathrm{C}$ until subsequent microbial analysis. A separate sample of rumen digesta was obtained at 0,6 , and $12 \mathrm{~h}$ after feeding on $\mathrm{d} 22$ and 28 . The rumen digesta were collected by grabbing a handful from the same 5 locations (approximately $100 \mathrm{~mL}$ from each location). These digesta samples were combined to one sample per cow per sampling time, and strained through 2 layers of perforated fabric (WeedBlock, Easy Gardener, Waco, TX) to obtain rumen fluid samples. Thus, a $15-\mathrm{mL}$ sample of rumen fluid was obtained and placed on ice until centrifugation at $3,000 \times g$ for 20 min at $4^{\circ} \mathrm{C}$ and subsequently stored at $-20^{\circ} \mathrm{C}$. Rumen fluid samples were thawed and pooled to 1 sample per cow per period accounting for diurnal variation, and stored at $-20^{\circ} \mathrm{C}$ until subsequent VFA profile analysis.

Enteric methane emissions from individual cows were measured consecutively for $5 \mathrm{~d}$ (d 23-27) using the sulfur hexafluoride $\left(\mathrm{SF}_{6}\right)$ tracer gas technique (Johnson et al., 1994), as modified by McGinn et al. (2006), using halters and polyvinyl chloride neck yokes (approximately $2 \mathrm{~L}$ of internal capacity). The halters and yokes were designed to allow for a $50 \%$ reduction in yoke vacuum over $24 \mathrm{~h}$ by an in-line stainless steel capillary tube. Brass permeation tubes $(12.5 \times 40 \mathrm{~mm})$ containing pure $\mathrm{SF}_{6}$ were sourced from $\mathrm{A}$. Iwaasa and stored at $39^{\circ} \mathrm{C}$ for at least 3 mo before the study start date to determine release rates. The mean release rates were $3.25 \pm 0.41$ and $3.20 \pm 0.23 \mathrm{mg} / \mathrm{d}$ (mean $\pm \mathrm{SD}$ ) for groups 1 and 2, respectively. Permeation tubes were placed in the rumen of individual cows $1 \mathrm{wk}$ before the beginning of the study. One week before methane collection, cows were adapted to halters and yokes placed around the neck for methane emission measurement.

For methane emission measurement, air was evacuated from yokes and they were placed on each animal at $0700 \mathrm{~h}$ on $\mathrm{d} 23$, and yokes and halters were replaced every $24 \mathrm{~h}$ until d 27 . Halters were checked daily for line blockages using pure nitrogen $\left(\mathrm{N}_{2}\right)$. Yokes were pressurized with $\mathrm{N}_{2}$ and allowed to sit for $1 \mathrm{~h}$, to obtain representative samples, and three 20-mL subsamples were taken from each yoke with a syringe, and injected into 6.8-mL containers for further analysis. Following sampling, yokes were cleaned 3 times by pressurizing with $\mathrm{N}_{2}$, sitting for $1 \mathrm{~h}$, and depressurizing. Yokes were again pressurized and allowed to sit until the following day to check for leakages, and used again for sample collection if no leakages were confirmed. Background concentrations of methane and $\mathrm{SF}_{6}$ in the animal facility were determined by suspending halters and yokes in front of and above cows during the sample collection period. Background yokes were treated in the same manner as yokes on cows but halters were not changed on a daily basis.

\section{Sample Analysis}

Dried feed samples were ground through a 1-mm screen with a Wiley mill (Thomas-Wiley, Philadelphia, PA) and sent to Cumberland Valley Analytical Services (Hagerstown, MD) for analysis. Dry matter was determined by drying samples at $135^{\circ} \mathrm{C}$ for $2 \mathrm{~h}$ (AOAC International, 2000; method 930.15) and OM was determined after 4 -h combustion at $550^{\circ} \mathrm{C}$ (AOAC International, 2000; method 942.05). Crude protein concentration was determined by flash combustion with gas chromatography and thermal conductivity detection (AOAC International, 2000; method 990.03). The NDF concentration was determined using sodium sulfite and amylase (Van Soest et al., 1991), and ADF was determined by boiling samples in an acidic solution followed by filtration (AOAC International, 2000; method 973.18). Crude fat was determined using a Tecator Soxtec System HT 1043 extraction unit (Tecator, Eden Prairie, MN) according to AOAC method 2003.05 (AOAC International, 2006) and starch concentration was determined as described in Hall (2009). Milk samples were individually analyzed for concentrations of milk fat, CP, lactose, MUN, and SCC contents at the Alberta Central Milk Testing Laboratory (Edmonton, AB, Canada; AOAC International, 2002). Rumen 
fluid samples were centrifuged at $12,000 \times g$ for $10 \mathrm{~min}$ and supernatant was collected and analyzed for VFA concentration by gas chromatography as described by Schlau et al. (2012).

Frozen rumen content (about 0.5-1 g) was thawed on ice and processed for DNA extraction. The beadbeating method was used to extract total DNA from the rumen digesta using the protocol outlined by Guan et al. (2008). After extraction, the concentration and quality of DNA was measured at A260 and A280 using an ND-1000 spectrophotometer (NanoDrop Technologies, Wilmington, DE).

Following DNA extraction, DNA samples (50 ng/uL) were used for estimation of total populations of bacteria and methanogenic Archaea in rumen digesta by measuring the copy numbers of $16 \mathrm{~s}$ rDNA gene using qPCR. The primer pair U2 (forward, 5'-ACTCCTACGGGAGGCAG-3'; reverse, 5'-GACTACCAGGGTATCTAATCC-3'; Stevenson and Weimer, 2007) was used to detect the copy numbers of total bacteria and the primer pair uniMet (forward, 5'-CCGGAGATGGAACCTGAGAC-3'; reverse, 5'-CGGTCTTGCCCAGCTCTTATTC-3'; Zhou et al., 2009) was used to detect the copy numbers of total methanogenic Archaea. All qPCR was performed with SYBR green chemistry (Fast SYBR green master mix; Applied Biosystems, Burlington, ON, Canada) using the StepOnePlus real-time PCR system (Applied Biosystems). The amplification program included a fast cycle and a melting curve section. The program used for total bacteria was $95^{\circ} \mathrm{C}$ for $5 \mathrm{~min}$, followed by 40 cycles at $95^{\circ} \mathrm{C}$ for $20 \mathrm{~s}$ and $62^{\circ} \mathrm{C}$ for $30 \mathrm{~s}$, whereas the program for total methanogenic Archaea was $95^{\circ} \mathrm{C}$ for $5 \mathrm{~s}$ for initial denaturation and then 40 cycles of $95^{\circ} \mathrm{C}$ for $10 \mathrm{~s}$, followed by annealing or extension for $30 \mathrm{~s}$ at $60^{\circ} \mathrm{C}$. The final melting curve detection of both microbes were the same, with $95^{\circ} \mathrm{C}$ for $15 \mathrm{~s}, 60^{\circ} \mathrm{C}$ for $1 \mathrm{~min}$, and $95^{\circ} \mathrm{C}$ for $15 \mathrm{~s}$ with fluorescence collection at $0.1^{\circ} \mathrm{C}$ intervals. The standard curves were constructed using a serial dilution of plasmid 16S rDNA from clones Butyrivibrio hungatei (Li et al., 2009) and Methanobrevibacter spp. strain AbM4 (Zhou et al., 2010) for total bacteria and methanogenic Archaea, respectively. The final copy numbers of 16s rDNA of targeted microbes, per gram of rumen digesta, were calculated as described by Chen et al. (2012). The initial copy numbers of the standard curve were calculated based on the formula $(\mathrm{NL} \times \mathrm{A}$ $\left.\times 10^{-9}\right) /(660 \times n)$, where NL is the Avogadro constant $\left(6.02 \times 10^{23}\right.$ molecules per mole $), \mathrm{A}$ is the molecular weight of the molecule in standard, and $n$ is the length of the amplicon (bp). The serial dilution was assigned from $10^{-3}$ to $10^{-8}$.

Total protozoa were estimated by analyzing the total copy number of $18 \mathrm{~S}$ rRNA genes with primer pair
P-SSU-316F (5'-CTTGCCCTCYAATCGTWCT-3'; Huws et al., 2009) and P-SSU-539R (5'-GCTTTCGWTGCTAGTGTATT-3') using qPCR with SYBRGreen Chemistry. The standard curve was constructed using plasmid DNA containing a cloned sequence (223 bp) using the same primer set that has been confirmed by BLAST (http://blast.ncbi.nlm.nih.gov/Blast.cgi) searches against Entodinium longinucleatum 18S rRNA gene (Accession number AB481099). The qPCR was performed using a fast cycle and a melting curve section. The program was $95^{\circ} \mathrm{C}$ for $5 \mathrm{~s}$ for initial denaturation and then 40 cycles of $95^{\circ} \mathrm{C}$ for $10 \mathrm{~s}$, followed by annealing or extension for $30 \mathrm{~s}$ at $60^{\circ} \mathrm{C}$. The final melting curve detection of protozoa was $95^{\circ} \mathrm{C}$ for $15 \mathrm{~s}, 60^{\circ} \mathrm{C}$ for $1 \mathrm{~min}$, and $95^{\circ} \mathrm{C}$ for $15 \mathrm{~s}$ with fluorescence collection at $0.1^{\circ} \mathrm{C}$ intervals. Similarly, the copy number of total protozoa 18S rRNA genes per gram of rumen digesta was calculated using the same formula as described for total bacteria and methanogenic Archaea.

Gas samples taken from the yokes were analyzed at the Lethbridge Research Centre (Lethbridge, AB, Canada) for concentrations of $\mathrm{SF}_{6}$ and methane using gas chromatography (model 5890, Agilent Technologies, Santa Clara, CA) with flame-ionization detection for methane and electron capture detection for sulfur hexafluoride using the method described by Chung et al. (2011). The $\mathrm{SF}_{6}$-to-methane ratio, corrected for background levels, was determined for each sample according to McGinn et al. (2006). Daily methane emission data were averaged to report one value per cow per period, and data from cows with less than $2 \mathrm{~d}$ of successful measurements were excluded from statistical analysis.

\section{Calculation and Statistical Analysis}

Yield of $4 \%$ FCM was calculated according to the equation $4 \% \mathrm{FCM}=[$ milk yield $(\mathrm{kg}) \times 0.4]+[$ fat yield $(\mathrm{kg}) \times 15]$, and ECM yield was calculated by an equation developed by Tyrrell and Reid (1965): ECM $=[$ milk yield $(\mathrm{kg}) \times 0.327]+[$ fat yield $(\mathrm{kg}) \times 12.95]$ + [protein yield $(\mathrm{kg}) \times 7.25]$. Feed efficiency was calculated as $4 \%$ FCM (kg) divided by kilograms of DMI. Energy expenditure to maintenance, milk production, change in BW, and methane was calculated according to NRC (2001). Gross energy intake from feed was calculated using the NRC (2001) formula: gross energy $(\mathrm{Mcal} / \mathrm{kg})=[0.0415 \times$ carbohydrate $(\%)]+[0.094 \times$ fat $(\%)]+[0.057 \times$ protein $(\%)]$.

Data were analyzed using the MIXED procedure of SAS (version 9.2; SAS Institute Inc., Cary, NC) according to the model

$$
\mathrm{Y}_{i j k l}=\mu+\mathrm{P}_{i}+\mathrm{T}_{j}+\mathrm{R}_{k}+\mathrm{C}(\mathrm{R})_{l(k)}+\mathrm{e}_{i j k l},
$$


where $\mathrm{Y}_{i j k l}$ is the dependent variable, $\mu$ is overall mean, $\mathrm{P}_{i}$ is fixed effect of period, $\mathrm{T}_{j}$ is fixed effect of treatment, $\mathrm{R}_{k}$ is fixed effect of parity, $\mathrm{C}(\mathrm{R})_{l(k)}$ is random effect of cow nested in parity, and $\mathrm{e}_{i j k l}$ is the residual error. Effects of group and parity $\times$ treatment interaction were originally included in the model, but were removed from the final statistical model, as their effects were not significant for primary response variables. Significance was declared when $P<0.05$ and tendencies were discussed when $P<0.10$.

\section{RESULTS}

The success rate for methane emission measurement was $64 \%$. Of the unsuccessful measurements, $92 \%$ were caused by damages to the halters or yokes and the remaining $8 \%$ were due to inadequate amounts of $\mathrm{SF}_{6}$ in gas subsamples, resulting in the inability to calculate methane emissions correctly. As the methane emission data with less than $2 \mathrm{~d}$ of successful measurements were excluded from statistical analysis, 5 data points were treated as missing values. Final $\mathrm{n}$ values were 8 and 11 for CON and NOP, respectively. Overall concentration of methane and $\mathrm{SF}_{6}$ found in yokes placed on cows yielding a successful measurement was $36.8 \pm 24.6$ ppm and $49.2 \pm 27.8 \mathrm{ppt}$ (mean $\pm \mathrm{SD}$ ), respectively. In background yokes, concentrations of methane and $\mathrm{SF}_{6}$ were $10.3 \pm 4.6 \mathrm{ppm}$ and $9.48 \pm 5.92 \mathrm{ppt}($ mean $\pm \mathrm{SD})$, respectively. For successful measurements, coefficient of variation for daily methane emission data within cow was 23.6 and $22.7 \%$ for NOP and CON, respectively, and they did not differ $(P=0.97)$.

Feeding $2,500 \mathrm{mg} / \mathrm{d}$ of NOP did not affect DMI compared with CON (Figure 1A). Cows fed NOP had decreased methane emissions (132 vs. $372 \mathrm{~g} / \mathrm{d}$; SEM $=23.1 ; P<0.0001)$, even when normalized for DMI (7.18 vs. 17.8 g/kg DMI; Figure 1B) or expressed as a percentage of gross energy intake (2.20 vs. $5.45 \%$; SEM $=0.31 ; P<0.0005)$ when compared with CON. Milk yield and milk component concentration were not affected when cows were fed NOP compared with CON (Table 2). Furthermore, when milk yield was corrected for milk fat or energy content, no differences between treatments were observed. However, BW gain was greater when cows were fed NOP compared with CON (1.06 vs. $0.39 \mathrm{~kg} / \mathrm{d} ; P=0.05)$, but feed efficiency was not affected by treatment.

Feeding NOP did not affect total concentration of VFA; however, it reduced the molar proportion of acetate $(52.1$ vs. $55.5 \mathrm{~mol} / 100 \mathrm{~mol}$ of VFA; $P=0.04$; Table 3 ) and tended to increase the proportion of propionate (26.4 vs. $23.9 \mathrm{~mol} / 100 \mathrm{~mol}$ of VFA; $P=$ $0.06)$ when compared with CON. This resulted in a decreased acetate-to-propionate ratio when cows were fed
NOP (2.02 vs. $2.36 ; P=0.04)$ compared with CON. No treatment effects were observed for other VFA. Total methanogen copy numbers were reduced with feeding of NOP $\left(0.95\right.$ vs. $2.69 \times 10^{8} / \mathrm{g}$ of rumen digesta; $P$ $=0.001)$ compared with CON, but total bacteria and protozoa copy numbers were not affected by treatment. A tendency was observed for a positive relationship between methanogen count number and methane emissions normalized for DMI $(P=0.08 ; \mathrm{y}=8.89+2.05$ $\left.\times 10^{8} \mathrm{x}, \mathrm{r}^{2}=0.16\right)$.
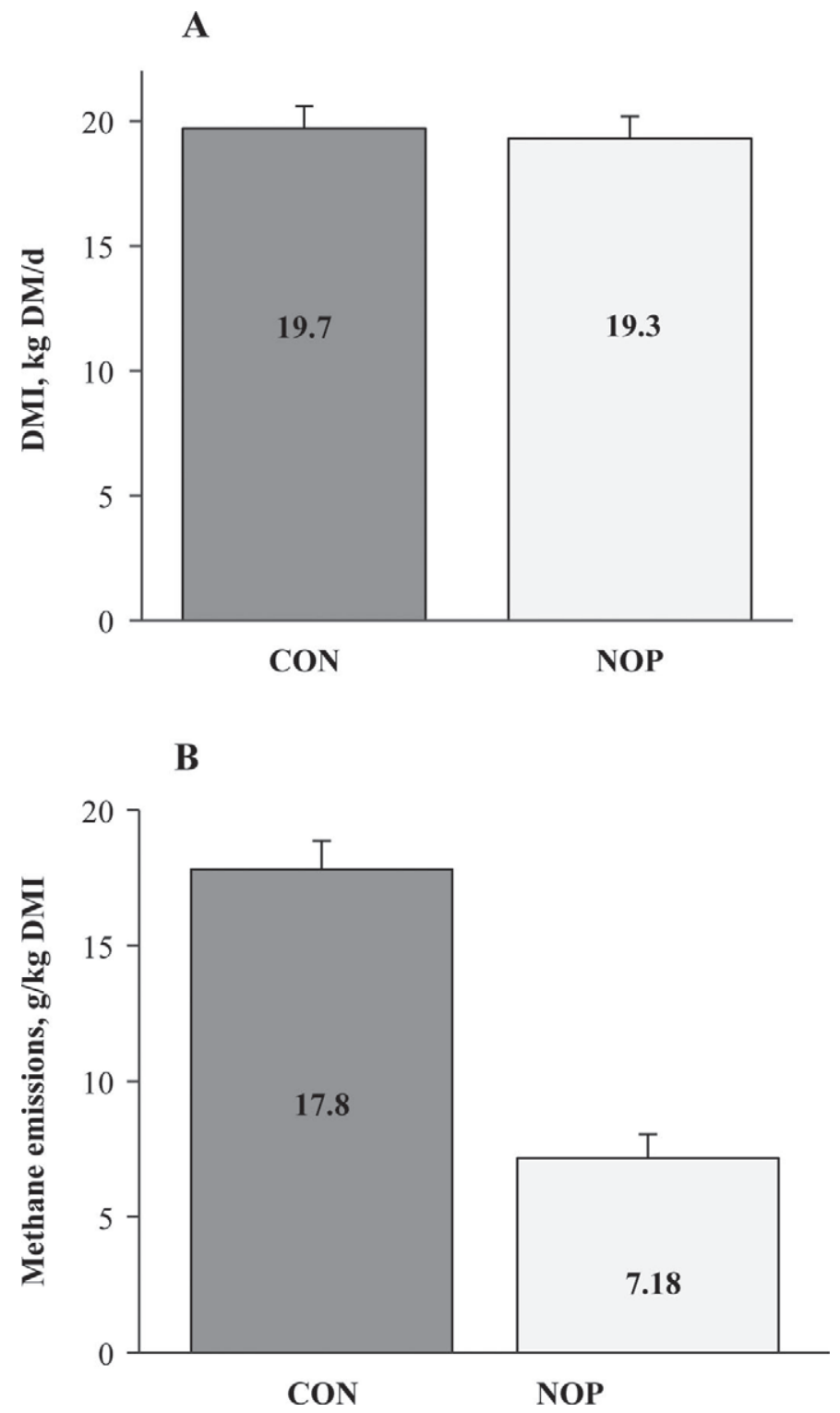

Figure 1. Effects of feeding 2,500 mg/d of 3-nitrooxypropanol (NOP) or $25 \mathrm{~g} / \mathrm{d}$ of silicone dioxide (CON) to lactating dairy cows on DMI (A; SEM $=0.66 ; P=0.36 ; \mathrm{n}=12$ for both CON and NOP $)$ and methane emissions (B; SEM $=0.95 ; P<0.001 ; \mathrm{n}=8$ and 11 for $\mathrm{CON}$ and NOP, respectively). 
Table 2. The effects of feeding 3-nitrooxypropanol (NOP) to lactating dairy cows on body weight change, milk yield, and milk components

\begin{tabular}{|c|c|c|c|c|}
\hline \multirow[b]{2}{*}{ Variable } & \multicolumn{2}{|c|}{ Treatment $^{1}$} & \multirow[b]{2}{*}{ SE } & \multirow[b]{2}{*}{$P$-value } \\
\hline & $\mathrm{CON}$ & $\mathrm{NOP}$ & & \\
\hline BW change, $\mathrm{kg} / \mathrm{d}$ & 0.39 & 1.06 & 0.21 & 0.05 \\
\hline Milk yield, $\mathrm{kg} / \mathrm{d}$ & 35.6 & 34.5 & 1.32 & 0.30 \\
\hline Milk fat, ${ }^{2} \%$ & 3.31 & 3.63 & 0.22 & 0.13 \\
\hline Milk CP, \% & 3.13 & 3.12 & 0.07 & 0.73 \\
\hline Milk lactose, $\%$ & 4.65 & 4.65 & 0.03 & 0.98 \\
\hline $4 \%$ FCM yield, ${ }^{2} \mathrm{~kg} / \mathrm{d}$ & 31.5 & 32.3 & 1.25 & 0.42 \\
\hline ECM yield,$^{2} \mathrm{~kg} / \mathrm{d}$ & 34.6 & 35.0 & 1.20 & 0.56 \\
\hline Feed efficiency, ${ }^{2} \%$ FCM/DMI & 1.60 & 1.69 & 0.06 & 0.26 \\
\hline
\end{tabular}

${ }^{1} \mathrm{Control}(\mathrm{CON})=25 \mathrm{~g} / \mathrm{d}$ of silicone dioxide; $\mathrm{NOP}=2,500 \mathrm{mg} / \mathrm{d}$ of 3-nitrooxypropanol; $\mathrm{n}=12$ for both CON and NOP, unless otherwise noted.

${ }^{2}$ One data point for milk fat content was removed due to being an outlier, resulting in $\mathrm{n}=12$ and 11 for CON and NOP, respectively.

\section{DISCUSSION}

One of the primary objectives of the current study was to determine the effects of NOP on methane emissions of lactating dairy cows without moving them to metabolic chambers. By using the $\mathrm{SF}_{6}$ tracer gas technique, we found that feeding $2,500 \mathrm{mg} / \mathrm{d}$ of NOP to lactating dairy cows reduced methane emissions by $60 \%$ without a reduction in DMI. The observed reduction in methane emission is slightly lower than that reported in vitro (Romero Perez et al., 2013b) but far greater than previously observed when the compound was tested in vivo (Martinez-Fernandez et al., 2013; Reynolds et al., 2013). Romero Perez et al. (2013b) measured in vitro methane production using a rumen simulation technique and found that methane production was reduced by $75 \%$. However, it is important to note that this reduction was seen in an in vitro system where $5 \mathrm{mg} / \mathrm{d}$ of NOP was added to $10 \mathrm{~g} / \mathrm{d}$ of feedstuff compared with $2,500 \mathrm{mg} / \mathrm{d}$ of NOP in $19.5 \mathrm{~kg}$ of DMI in an in vivo setting. In comparison to other in vivo studies, when $100 \mathrm{mg} / \mathrm{d}$ of NOP was dosed directly in the rumen of sheep fed a $60 \%$ forage diet, methane emission was reduced by $23 \%$ (Martinez-Fernandez et al., 2013). Similarly, when $2,500 \mathrm{mg} / \mathrm{d}$ was dosed directly into the rumen of lactating dairy cattle, methane emission was reduced by 10\% (Reynolds et al., 2013). When $2,720 \mathrm{mg} / \mathrm{d}$ was top-dressed on to a $60 \%$ forage TMR fed to beef heifers, methane emission was reduced by $33 \%$ (Romero Perez et al., 2013a).

All previous in vivo studies evaluating NOP were conducted using chambers to measure methane emissions, whereas the current study used the $\mathrm{SF}_{6}$ tracer gas technique. However, greater reduction in methane emission from lactating dairy cows in the current study cannot be explained by difference in methodology alone because we used a crossover design in which each animal serves as their own control. Any potential bias or

Table 3. The effects of feeding 3-nitrooxypropanol (NOP) to lactating dairy cows on VFA profile of rumen fluid and bacterial profile counts

\begin{tabular}{|c|c|c|c|c|}
\hline \multirow[b]{2}{*}{ VFA } & \multicolumn{2}{|c|}{ Treatment $^{1}$} & \multirow[b]{2}{*}{$\mathrm{SE}$} & \multirow[b]{2}{*}{$P$-value } \\
\hline & $\mathrm{CON}$ & NOP & & \\
\hline Total, $\mathrm{m} M$ & 103 & 109 & 5.29 & 0.39 \\
\hline Acetate, $\mathrm{mol} / 100 \mathrm{~mol}$ of VFA & 55.5 & 52.1 & 1.08 & 0.04 \\
\hline Propionate, $\mathrm{mol} / 100 \mathrm{~mol}$ of VFA & 23.9 & 26.4 & 0.85 & 0.06 \\
\hline Butyrate, mol/100 mol of VFA & 14.3 & 14.8 & 0.85 & 0.59 \\
\hline Isobutyrate, $\mathrm{mol} / 100 \mathrm{~mol}$ of VFA & 1.10 & 1.08 & 0.06 & 0.82 \\
\hline Valerate, mol/100 mol of VFA & 2.25 & 2.57 & 0.19 & 0.27 \\
\hline Isovalerate, $\mathrm{mol} / 100 \mathrm{~mol}$ of VFA & 1.84 & 2.02 & 0.14 & 0.15 \\
\hline Caproate, mol/100 mol of VFA & 1.17 & 1.06 & 0.25 & 0.62 \\
\hline Acetate-to-propionate ratio & 2.36 & 2.02 & 0.15 & 0.04 \\
\hline Total bacteria copy numbers, $\times 10^{10} / \mathrm{g}$ of rumen digesta & 34.5 & 20.5 & 5.62 & 0.11 \\
\hline Methanogen copy numbers, $\times 10^{8} / \mathrm{g}$ of rumen digesta & 2.69 & 0.95 & 3.01 & 0.001 \\
\hline Protozoa copy numbers, $\times 10^{5} / \mathrm{g}$ of rumen digesta & 1.69 & 1.35 & 0.25 & 0.25 \\
\hline
\end{tabular}

${ }^{1}$ Control $(\mathrm{CON})=25 \mathrm{~g} / \mathrm{d}$ of silicone dioxide; $\mathrm{NOP}=2,500 \mathrm{mg} / \mathrm{d}$ of 3-nitrooxypropanol; $\mathrm{n}=12$ for both CON and NOP. 
errors leading to less accurate methane measurement would therefore affect both NOP treatment and CON, and, as such, would not affect the evaluation of the effects due to treatment. However, the coefficient of variation for daily methane measurements using $\mathrm{SF}_{6}$ tracer gas technique exceeded $20 \%$ in the current study, suggesting that this technique would not be appropriate to evaluate minor treatment effects on methane emissions. It has been suggested that cannulated animals not be used with the $\mathrm{SF}_{6}$ tracer gas technique due to an increase in variability (Beauchemin et al., 2012). However, we were able to detect significant treatment effects of NOP on methane emissions with $\mathrm{SF}_{6}$ tracer gas technique partly because of the great magnitude of reduction. Despite the inherent technical problem, the $\mathrm{SF}_{6}$ tracer gas technique was considered advantageous for our study, as it allowed for animals to stay in their normal environment, and treatment effects on DMI and animal performance were determined while methane emissions were being measured.

One possible explanation for a higher reduction in methane emissions in the current study, compared with previous in vivo trials, could be that the compound was mixed into the TMR. This approach might have allowed the cows to consume NOP throughout the day as feed was ingested compared with dosing into the rumen. When NOP was dosed into the rumen of dairy cattle, Reynolds et al. (2013) found that methane production dropped substantially immediately after dosing, but the effect was only sustained for 1 to $2 \mathrm{~h}$. It was hypothesized that this fast decrease in efficacy was likely linked to the very high solubility of the compound that would rapidly leave the rumen, particularly in high-producing dairy cows with decreased rumen retention time. Additionally, the reduction in methane emission after dosing may coincide with the period that methanogens are expected to be highest. Leedle and Greening (1988) found that when steers were fed a $25 \%$ forage diet, methanogen counts increased shortly after feeding, dropped, and then continued to rise throughout the day $\left(3.7 \times 10^{8} / \mathrm{g}\right.$ of ruminal contents at $4 \mathrm{~h}$ postfeeding vs. $8.3 \times 10^{8} / \mathrm{g}$ of ruminal content at 20 $\mathrm{h}$ postfeeding). Allowing for continual consumption of NOP over a 24 -h period, as was done in the current study, could potentially lead to a sustained reduction of methane production throughout the day. As cows were fed a TMR ad libitum, allowing for $5 \%$ refusal in the current study, actual NOP intake could have been lower than $2,500 \mathrm{mg} / \mathrm{d}$ for some animals. Although actual NOP intake and consistency of NOP supply to the animal were not determined in the current study, our data suggest that mixing the compound in TMR is more effective at reducing methane emissions compared with dosing into the rumen directly.
In the current study, a tendency was observed for a positive relationship between number of methanogens and methane production (Figure 2); however, a direct cause-and-effect relationship between methanogen abundance and methane production has not been confirmed in the literature. Contrary to our results, previous work by Martinez-Fernandez et al. (2013) found no difference in microbial profile in sheep dosed with NOP; similarly, Romero Perez et al. (2013a) reported that total methanogen counts were not affected by NOP. In both cases, the diet fed to the animals was $60 \%$ forage (DM basis) and they reported less reduction in methane emissions due to NOP compared with the current study, in which a $38 \%$ forage diet was fed. Hook et al. (2011) showed that the species of methanogens present in the rumen was different for a high-concentrate diet compared with a high-forage diet fed to nonlactating dairy cattle, whereas the level of concentrate did not affect total methanogen counts. Similarly, Zhou et al. (2010) found that, regardless of dietary energy content, the total population of methanogens present in the rumen of steers was not different; however, the predominant species differed. These previous data indicate that efficacy of NOP in reducing methane emissions might be diet-dependent, and that NOP may affect specific species of methanogens present to a greater extent in low-forage diets, which may partly explain greater animal responses to NOP in the current study compared with the other in vivo studies (Martinez-Fernandez et al., 2013; Reynolds et al., 2013; Romero Perez et al., 2013a).

In addition, ecto- and endosymbiotic relationships exist between protozoa and some methanogens, and their contribution is estimated at up to $37 \%$ of total methane production in the rumen (Dohme et al., 1999; Hegarty, 1999; McAllister and Newbold, 2008). A relationship between methane production, methanogens, and protozoa counts often exists. In particular, when effects of feeding lipids are assessed, a reduction in protozoa is often observed along with a reduction in methane (Dohme et al., 1999; Beauchemin et al., 2009b). In the current study, no change in protozoa counts was observed when NOP was fed; as such, the reduction in methanogens may not be attributed to changes in protozoa, but to the direct effects of NOP on methanogen counts or their function. The current data further support the suggestion that NOP reduces methane formation through impeding methanogenesis, thus reducing methanogen counts. This effect could be diet-dependent, therefore allowing for a species-specific response, which would explain the discrepancy in results between the current study and other studies using NOP in vivo. As such, further research is warranted to determine whether abundance of specific methanogen 


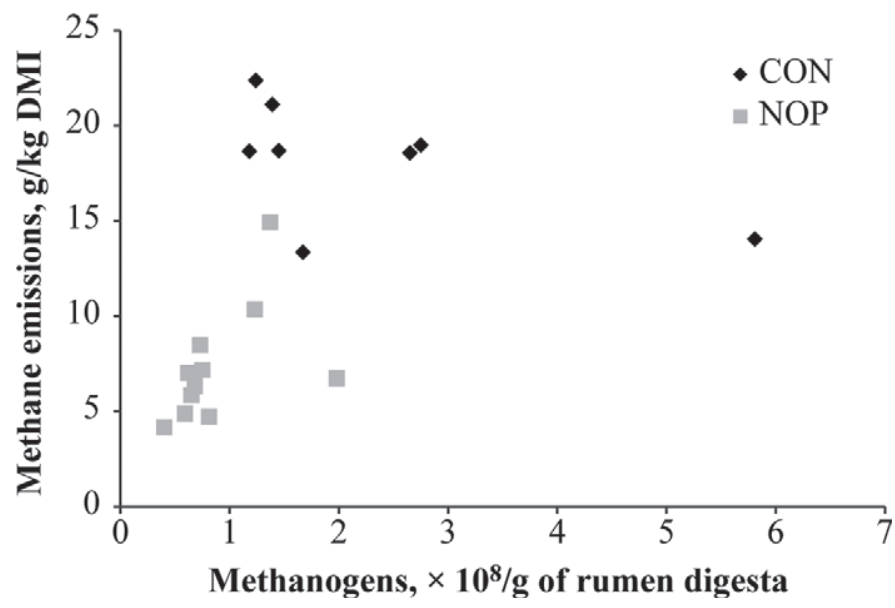

Figure 2. Relationship between methanogen counts and methane emission per kilogram of DMI when 2,500 mg/d of 3-nitrooxypropanol (NOP) or $25 \mathrm{~g} / \mathrm{d}$ of silicone dioxide $(\mathrm{CON})$ was added to the diet of lactating dairy cows ( $\mathrm{n}=8$ and 11 for $\mathrm{CON}$ and NOP, respectively). A tendency was observed for the overall relationship between methanogens and methane emissions $\left(P=0.08 ; \mathrm{y}=8.89+2.05 \times 10^{8}, \mathrm{r}^{2}\right.$ $=0.16)$.

species is affected when NOP is supplemented in the diet.

The decrease in acetate concentration, tendency toward increased propionate concentration in ruminal fluid, and resulting reduction in acetate-to-propionate ratio is consistent with the inverse relationship reported for methane and propionate (Mathison et al., 1998). Promoting propionate production in the rumen can reduce methane production, as it acts as an alternate hydrogen sink (Kobayashi, 2010). Alternatively, a reduction in methane can cause an increase in propionate production, and the lower acetate-to-propionate ratio observed in the current study supports that propionate production acted at least partly as an alternate pathway for hydrogen. Similarly, other research has found a reduction in the acetate to propionate ratio when NOP is fed [3.89 vs. 4.91 (Martinez-Fernandez et al., 2013), 2.74 vs. 2.93 (Reynolds et al., 2013), and 2.1 vs. 3.3 (Romero Perez et al., 2013a)], suggesting fermentation in the rumen shifted toward propionate production. The authors acknowledge that the tendency for an increase in propionate concentration for NOP compared with CON would not exclusively explain the metabolic fate of available hydrogen, which is expected to increase from a $60 \%$ reduction in methane emissions. In an in vitro system, Immig (1996) studied the effects of 2-bromoethanesulfonic acid, a structural analog to coenzyme M that blocks the final step of methane formation, which is similar to the expected mode of action of NOP. They found a discrepancy between hydrogen produced during fermentation and recovered from the system through end products when methane was reduced. Those re- sults suggested additional hydrogen sinks, and through stoichiometric calculations they determined that an accumulation of formate, a precursor for methanogenesis, had occurred. As formate is readily metabolized in the rumen and difficult to measure in vivo (Hungate et al., 1970), further research is warranted to look at the effects of NOP on rumen fermentation pathways and alternate hydrogen sinks.

Contrary to our hypothesis, milk yield and milk component concentration were not affected, despite a substantial reduction in methane; however, cows fed NOP gained more BW compared with CON (1.06 vs. $0.39 \mathrm{~kg} / \mathrm{d}$ ). When Reynolds et al. (2013) dosed 2,500 $\mathrm{mg} / \mathrm{d}$ of NOP to midlactation cows, FCM yield was not affected and BW change was not reported. The results found in the current study could be due to the fact we used cows after peak lactation, and it has been found that partitioning of ME intake toward milk energy output decreases as lactation stage proceeds, whereas partitioning toward body tissue energy increases (Kirkland and Gordon, 2001).

To quantify the additional net energy provided by reduced methane emissions, energy outputs were calculated and compared between NOP and CON cows. When energy expenditures were calculated according to NRC (2001), net energy outputs toward maintenance (9.43 vs. $9.48 \mathrm{Mcal} / \mathrm{d}$ ) and lactation (23.8 vs. 23.6 Mcal/d) were similar between NOP and CON cows, respectively; however, NOP cows had more net energy output toward BW gain compared with CON cows (5.86 vs. $2.12 \mathrm{Mcal} / \mathrm{d}$ ). Assuming that energy outputs for heat, urine, and feces were not affected by treatment, the reduction in energy lost as methane (1.75 vs. $4.94 \mathrm{Mcal} / \mathrm{d}$ for CON and NOP, respectively) accounted for approximately $80 \%$ of the difference in total energy expenditures.

Given that cows used in the present study were in midlactation and the TMR fed was formulated to exceed their nutrient requirements for lactation, it is reasonable that excess $\mathrm{ME}$, due to a reduction in methane production, would go toward BW gain rather than lactation. As such, in future studies, it would be necessary to evaluate the effects of feeding NOP on milk production and energy partitioning of cows in early lactation. In moving forward with establishing the efficacy of feeding NOP to reduce methane emissions from ruminants, its effects on nutrient digestibility and metabolism should also be evaluated. In addition, the current study evaluated effects of NOP for relatively short periods (i.e., $28 \mathrm{~d}$ ) using a crossover design, in which possible confounding carryover effects of treatment cannot be excluded. A long-term study is warranted to determine effects of feeding NOP on rumen fermentation and animal performance more accurately. 


\section{CONCLUSIONS}

Feeding 2,500 mg/d of NOP reduced enteric methane emissions from lactating dairy cows by $60 \%$ without affecting DMI, and the reduction in methane emission was associated with decreased methanogen counts and acetate-to-propionate ratio in the rumen. In addition, although milk production was not affected by treatment, cows fed NOP increased BW gain, indicating that the reduction in methane emissions increased energy availability to animals.

\section{REFERENCES}

AOAC International. 2000. Official Methods of Analysis. 16th ed. AOAC International, Arlington, VA.

AOAC International. 2002. Official Methods of Analysis. 17th ed. AOAC International, Arlington, VA.

AOAC International. 2006. Official Methods of Analysis. 18th ed. AOAC International, Arlington, VA.

Beauchemin, K. A., T. A. McAllister, and S. M. McGinn. 2009a. Dietary mitigation of enteric methane from cattle. CAB Rev. Perspect. Agric. Vet. Sci. Nutr. Nat. Res. 4:1-18.

Beauchemin, K. A., S. M. McGinn, C. Benchaar, and L. Holtshausen. 2009b. Crushed sunflower, flax or canola seeds in lactating dairy cow diets: Effects on methane production, rumen fermentation and milk production. J. Dairy Sci. 92:2118-2127.

Beauchemin, K. A., T. Coates, B. Farr, and S. M. McGinn. 2012 Technical note: Can the sulfur hexafluoride tracer gas technique be used to accurately measure enteric methane production from ruminally cannulated cattle? J. Anim. Sci. 90:2727-2732.

Chen, Y., M. Oba, and L. L. Guan. 2012. Variation of bacterial communities and expression of Toll-like receptor genes in the rumen of steers differing in susceptibility to subacute ruminal acidosis. Vet. Microbiol. 159:451-459.

Chung, Y. -H., N. D. Walker, S. M. McGinn, and K. A. Beauchemin. 2011. Differing effects of 2 active dried yeast (Saccharomyces cerevisiae) strains on ruminal acidosis and methane production in nonlactating dairy cows. J. Dairy Sci. 94:2431-2439.

Dohme, F., A. Machmuller, B. L. Estermann, P. Pfister, A. Wasserfallen, and M. Kreuzer. 1999. The role of rumen ciliate protozoa for methane suppression caused by coconut oil. Lett. Appl. Microbiol. 29:187-192.

Duval, S., and M. Kindermann. 2012. Use of nitrooxy organic molecules in feed for reducing enteric methane emissions in ruminants, and/or to improve ruminant performance. World Intellectual Property Organization. International Patent Application WO 2012/084629 A1.

Eckard, R. J., C. Grainger, and C. A. M. de Klein. 2012. Options for the abatement of methane and nitrous oxide from ruminant production: A review. Livest. Sci. 130:47-56.

Guan, L. L., J. D. Nkrumah, J. A. Basarab, and S. S. Moore. 2008 Linkage of microbial ecology to phenotype: Correlation of rumen microbial ecology to cattle's feed efficiency. FEMS Microbiol. Lett. 288:85-91.

Gunsalus, R. P., J. A. Romesser, and R. S. Wolfe. 1978. Preparation of coenzyme $\mathrm{M}$ analogues and their activity in the methyl coenzyme $\mathrm{M}$ reductase system of Methanobacterium thermoautotrophicum. Biochemistry 17:2374-2377.

Hall, M. B. 2009. Analysis of starch, including maltooligosaccharides, in animal feeds: A comparison of methods and a recommended method for AOAC collaborative study. J. AOAC Int. 92:42-49.

Hegarty, R. S. 1999. Reducing rumen methane emissions through elimination of rumen protozoa. Aust. J. Agric. Res. 50:1321-1327.

Hook, S. E., M. A. Steele, K. S. Northwood, A. D. Wright, and B. W. McBride. 2011. Impact of high-concentrate feeding and low rumi- nal $\mathrm{pH}$ on methanogens and protozoa in the rumen of dairy cows. Microb. Ecol. 62:94-105.

Hungate, R. E., W. Smith, T. Bauchop, I. D. A. Yu, and J. C. Rabinowitz. 1970. Formate as an intermediate in the bovine rumen fermentation. J. Bacteriol. 102:389-397.

Huws, S. A., E. J. Kim, A. H. Kingston-Smith, M. R. F. Lee, S. M. Muetzel, C. J. Newbold, R. J. Wallace, and N. D. Scollan. 2009. Rumen protozoa are rich in polyunsaturated fatty acids due to the ingestion of chloroplasts. FEMS Microbiol. Ecol. 69:461-471.

Immig, I. 1996. The rumen and hindgut as source of ruminant methanogenesis. Environ. Monit. Assess. 42:57-72.

Johnson, K., M. Huyler, H. Westberg, B. Lamb, and P. Zimmerman. 1994. Measurement of methane emissions from ruminant livestock using a sulfur hexafluoride tracer technique. Environ. Sci. Technol. 28:359-362.

Johnson, K. A., and D. E. Johnson. 1995. Methane emissions from cattle. J. Anim. Sci. 73:2483-2492.

Kirkland, R. M., and F. J. Gordon. 2001. The effects of stage of lactation on the partitioning of, and responses to changes in, metabolisable energy intake in lactating dairy cows. Livest. Prod. Sci. $72: 213-224$

Kobayashi, Y. 2010. Abatement of methane production from ruminants: Trends in manipulation of rumen fermentation. Asian-australas. J. Anim. Sci. 23:410-416.

Leedle, J. A., and R. C. Greening. 1988. Postprandial changes in methanogenic and acidogenic bacteria in the rumens of steers fed high- or low-forage diets once daily. Appl. Environ. Microbiol. 54:502-506.

Li, M., G. B. Penner, E. Hernandez-Sanabria, M. Oba, and L. L. Guan. 2009. Effects of sampling location and time, and host animal on assessment of bacterial diversity and fermentation parameters in the bovine rumen. J. Appl. Microbiol. 107:1924-1934.

Martin, C., D. P. Morgavi, and M. Doreau. 2010. Methane mitigation in ruminants: From microbe to the farm scale. Animal 4:351-365.

Martinez- Fernandez, G., A. Arco, L. Abecia, G. Cantalapiedra-Hijar, E. Molina-Alcaide, A. I. Martin- Garcia, M. Kindermann, S. Duval, and D. R. Yanez-Ruiz. 2013. The addition of ethyl-3-nitrooxy propionate and 3-nitrooxypropanol in the diet of sheep substantially reduces methane emissions and the effect persists over a month. Adv. Anim. Biosci. 4:368. (Abstr.)

Mathison, G. W., E. K. Okine, T. A. McAllister, Y. Dong, J. Galbraith, and O. I. N. Dymytruk. 1998. Reducing methane emissions from ruminant animals. J. Appl. Anim. Res. 14:1-28.

McAllister, T. A., and C. J. Newbold. 2008. Redirecting rumen fermentation to reduce methanogenesis. Aust. J. Exp. Agric. 48:7-13.

McGinn, S. M., K. A. Beauchemin, A. D. Iwaasa, and T. A. McAllister. 2006. Assessment of the sulfur hexafluoride $\left(\mathrm{SF}_{6}\right)$ tracer technique for measuring enteric methane emissions from cattle. J. Environ. Qual. 35:1686-1691.

NRC. 2001. Nutrient Requirements of Dairy Cattle. 7th ed. Natl. Acad. Press, Washington, DC.

Reynolds, C. K., D. J. Humphries, P. Kirton, M. Kindermann, S. Duval, and W. Steinberg. 2013. Effects of incremental rumen doses of 3-nitrooxypropanol on methane production, digestion and rumen parameters in lactating dairy cows. Adv. Anim. Biosci. 4:261. (Abstr.)

Romero Perez, A., K. A. Beauchemin, S. M. McGinn, E. K. Okine, L. L. Guan, M. Oba, and S. M. Duval. 2013a. The potential of 3-nitrooxipropanol to lower enteric methane emissions from beef cattle. Adv. Anim. Biosci. 4:387. (Abstr.)

Romero Perez, A., K. A. Beauchemin, E. K. Okine, and S. M. Duval 2013b. Effects of 3-nitrooxipropanol on methane production using the rumen simulation technique (Rusitec). Adv. Anim. Biosci. 4:389. (Abstr.)

Schlau, N., L. L. Guan, and M. Oba. 2012. The relationship between rumen acidosis resistance and expression of genes involved in regulation of intracellular $\mathrm{pH}$ and butyrate metabolism of ruminal epithelial cells in steers. J. Dairy Sci. 95:5866-5875.

Soliva, C. R., S. L. Amelchanka, S. M. Duval, and M. Kreuzer. 2011. Ruminal methane inhibition potential of various pure compounds 
in comparison with garlic oil as determined with a rumen simulation technique (Rusitec). Br. J. Nutr. 106:114-122.

Stevenson, D. M., and P. J. Weimer. 2007. Dominance of Prevotella and low abundance of classical ruminal bacterial species in the bovine rumen revealed by relative quantification real-time PCR. Appl. Microbiol. Biotechnol. 75:165-174.

Tyrrell, H. F., and J. T. Reid. 1965. Prediction of the energy of cow's milk. J. Dairy Sci. 48:1215-1223.

United Nations. 2013. Framework Convention on Climate Change. Global Warming Potentials. Accessed Nov. 18, 2013. http:// unfccc.int/ghg_data/items/3825.php.
Van Soest, P. J., J. B. Robertson, and B. A. Lewis. 1991. Methods for dietary fiber, neutral detergent fiber, and nonstarch polysaccharides in relation to animal nutrition. J. Dairy Sci. 74:3583-3597.

Zhou, M., E. Hernandez-Sanabria, and L. L. Guan. 2009. Assessment of the microbial ecology of ruminal methanogens in cattle with different feed efficiencies. Appl. Environ. Microbiol. 75:6524-6533.

Zhou, M., E. Hernandez-Sanabria, and L. L. Guan. 2010. Characterization of variation in rumen methanogenic communities under different dietary and host feed efficiency conditions, as determined by PCR-denaturing gradient gel electrophoresis analysis. Appl. Environ. Microbiol. 76:3776-3786. 